\title{
Innovative Consortia of Micro and Macro Fungal Systems: Cellulolytic Enzyme Production from Groundnut Shell Biomass and Supportive Structural Analysis
}

\author{
Sai Praneeth Thota1, Pradeep Kumar Badiya1, Yadhu Nadh Guragain², \\ Praveen Venkata Vadlani ${ }^{2}$, Meera Pandey ${ }^{3}$, Rajesh Babu Dandamudi, \\ Sai Sathish Ramamurthy ${ }^{1}$, Siva Kumar Belliraj ${ }^{*}$ \\ ${ }^{1}$ Department of Chemistry, Sri Sathya Sai Institute of Higher Learning, Prasanthi Nilayam, India \\ ${ }^{2}$ Bioprocessing and Renewable Energy Laboratory, Departments of Grain Science and Industry \& Chemical Engineering, Kansas \\ State University, Manhattan, KS, USA \\ ${ }^{3}$ Mushroom Lab, Indian Institute Horticulture Research, Bangalore, India \\ Email: ^bsivakumar@sssihl.edu.in
}

How to cite this paper: Thota, S.P., Badiya, P.K., Guragain, Y.N., Vadlani, P.V., Pandey, M., Dandamudi, R.B., Ramamurthy, S.S. and Belliraj, S.K. (2018) Innovative Consortia of Micro and Macro Fungal Systems: Cellulolytic Enzyme Production from Groundnut Shell Biomass and Supportive Structural Analysis. Journal of Sustainable Bioenergy Systems, 8, 47-66. https://doi.org/10.4236/jsbs.2018.83004

Received: July 7, 2018

Accepted: September 3, 2018

Published: September 6, 2018

Copyright $\odot 2018$ by authors and Scientific Research Publishing Inc. This work is licensed under the Creative Commons Attribution International License (CC BY 4.0).

http://creativecommons.org/licenses/by/4.0/

\section{(c) (i) Open Access}

\begin{abstract}
Renewable biomass-derived fuels are essential to meet the blend mandates and the sustainability goals. In our first-to-date study, we investigated individual and synergistic consortia of fungal cultures comprising Pycnoporous sanguineus (PS) in combination with Aspergillus oryzae (AO) and Trichoderma harzianum $(T H)$ for production of cellulolytic enzymes using groundnut shell under solid state and submerged liquid fermentation conditions. The innovative consortia closely align with the microbial ecosystems found in nature; consequently, we anticipate a potent and effective cellulolytic enzyme system, which maximises the breakdown of biomass polymers to sugars. Under ternary combination of cultures, cellulase production was highest at $123.0 \pm 1 \mathrm{FPU} / \mathrm{gds} ; \beta$-glucosidase production at $875.6 \pm 26.4 \mathrm{IU} / \mathrm{g}$ dry substrate (gds); and CMCase at $474.95 \pm 45.5 \mathrm{IU} / \mathrm{gds}$. $\beta$-glucosidase production was highest on the $2^{\text {nd }}$ day at $987.03 \pm 64.2 \mathrm{IU} / \mathrm{gds}$ while CMCase peaked at $514.97 \pm 21.4 \mathrm{IU} / g d s$ on $2^{\text {nd }}$ day for PS, maximum cellulase enzyme production was observed on the $6^{\text {th }}$ day at $192.2 \pm 0.96 \mathrm{FPU} / \mathrm{gds}(\mathrm{AO}+\mathrm{PS})$. Present work showed that synergistic combination of fungal cultures for releasing balanced enzyme activities that can efficiently saccharify biomass, such as groundnut shell to sugars, which can subsequently be fermented to various bioproducts and biomaterial monomers. Elaborate characterization studies of enzyme treated groundnut shell revealed prominent physicochemical changes in the hydrolysate, which indicates the changes in biomass
\end{abstract}


are due to the enzymatic action and the growth effects of the consortia; thereby, leading to promising applications for the microbial fortified biomass.

\section{Keywords}

Mixed Cultures, Fermentation, Enzymatic Hydrolysis, Groundnut Shell, Biomass Characterization

\section{Introduction}

Large-scale substitution of petroleum based fuels by renewable alternatives is imperative to tackle climate changes and energy security [1]. The fluctuating costs of fuel over the high demand in the past decade have inspired the research to generate fuel from renewable resources, particularly ethanol from biomass [2]. Biofuels not only reduces the environmental pollution due to its high oxygen content, but also reduces our reliance on oil imports and thus alleviating the uncertainties caused by oil price fluctuations [3].

Critics have raised the potential increase in food costs [4] along with food shortages globally if utilization of food based resources is diverted to produce biofuels [5]. Biofuels derived from biomass will alleviate these concerns and are more economical [6] compared with fuels from food crops such as grain corn and sugarcane. Thus, lignocellulosic biomass feed stocks present an attractive alternative energy source for sustainable energy production [7]. Non-food based sources such as wheat straw [8], wheat bran [9], rice straw [10], corn stover [11], maize [5], sorghum, kinnow mandarin [12], and bagasse have high potential. India is the second largest groundnut producer in the world after China with production of 8.22 million tons in 2017-18 [13]. In India, Andhra Pradesh ranks second after Gujarat with 3.80 lakh tons. The crop can grow successfully with minimum rainfall and in Anantapur region, $\left(14.16^{\circ} \mathrm{N}, 77.80^{\circ} \mathrm{E}\right)$ groundnut is a major cash crop. The quantity of groundnut shells (GNS) waste by-product generated after harvesting of groundnuts is substantial. GNS has created interest among researchers for application in energy production due to its composition, but cellulose is in the form of lignocellulose, hence the conversion to sugars [14].

Lignocelluloses conversion to fermentable sugars is performed by enzymatic hydrolysis of polysaccharides, preferentially with cellulases and hemicellulases resulting from biomass treatment [14]. However, the costs for these specialized enzyme systems are still significant in spite of dedicated efforts in industry and academia in the last decade. Cellulases and cellulolytic enzymes production at lower costs will substantially reduce the overall production costs of producing biofuels from lignocellulosic biomass [15]. To accomplish this, development of a highly efficient enzyme production process along with development of robust microbial strains for enzyme production is necessary [16]. Bioreactor operational modes such as solid state fermentation (SSF) and submerged fermentation (SmF) were developed for the production of enzymes at industrial scale [10]. SSF 
is well known to produce cellulases while utilizing biopolymers such as cellulose and hemi-cellulose from agricultural residues; thereby offering a potentially low-cost alternative. SmF operates in free-flowing liquid substrates [15].

Filamentous fungi are one of the major sources of cellulases and hemicellulases. Among prominent fungi, Aspergillus [17] and Trichoderma have been widely exploited. Trichoderma strains have been reported to produce high activities of both CMCase and exo-glucanase but have poor release of $\beta$-glucosidase, which causes accumulation of cellobiose [10]. Further, cellobiose accumulation leads to feedback inhibition by repressing of cellulase enzyme activity [18]. The strains of Aspergillus are known to have high $\beta$-glucosidase activity release [19]. Mixed cultures are known to produce enzyme cocktails which are rich in $\beta$-glucosidase; thus diminishing the accumulated cellobiose concentration as a result of formation of glucose [20].

To increase the enzymatic digestibility of lignocelluloses, most studies focused on use of soft-cellulolytic bacteria, white and brown-rot fungi [21]. Microorganisms release cellobiose dehydrogenase that can degrade the three polymers of biomass i.e., cellulose, hemicellulose, and lignin and therefore can effect complete lignocellulose degradation [22]. Combination of fungal treatments can significantly improve enzymatic digestibility and reduce the time needed for achieving high cellulolytic enzyme production. Although mono culture of endophytic fungi and/or co-culture of fungi were tried previously [23], there have been no retrievable studies found in literature which investigated the enzyme production with ternary combination of endophytic fungi, white rot fungi and filamentous fungi. Ternary combinations of fungi could possibly mimic the consortia that happen in natural degradation.

The current study was carried out to evaluate the cellulolytic enzymes production using mono and mixed-cultures, in SSF and SmF conditions on GNS with Aspergillus oryzae (AO, NCIM1212, micro fungi), Pycnoporous sanguineus (PS, wood decaying macro fungus) and Trichoderma harzianum (TH, endophytic fungus) independently and in combination as microbial systems. This innovative approach of using diverse consortia, nature-based, is first of its kind; the evaluation of its performance will result in significant and appropriate sustainable biomass processing of renewable resources for value added products.

\section{Materials and Methods}

\subsection{Chemicals and Microbial Strains}

Untreated GNS was purchased from local farmers in Puttaparthi, Anantapur, A.P, India. $\mathrm{NaOH}$ (Merck, >97\%), Potato dextrose agar (Himedia), Proteose peptone (Himedia), $\left(\mathrm{NH}_{4}\right)_{2} \mathrm{SO}_{4}$ (SDFCL), $\mathrm{KH}_{2} \mathrm{PO}_{4}$ (Merck), Urea (Merck), $\mathrm{MgSO}_{4} \cdot 7 \mathrm{H}_{2} \mathrm{O}$ (SDFCL), $\mathrm{CaCl}_{2} \cdot 2 \mathrm{H}_{2} \mathrm{O},(\mathrm{SDFCL}), \mathrm{ZnSO}_{4} \cdot 7 \mathrm{H}_{2} \mathrm{O}$ (SDFCL), $\mathrm{FeSO}_{4}$ (SDFCL, 99.5\%), $\mathrm{MnSO}_{4}$ (SDFCL, >98\%), $\mathrm{ZnCl}_{2}$ (SDFCL, >98\%), Dinitro-salicylic acid (Sigma Aldrich), Cellulose (Sigma ALdrich), filter paper (Whatman No.1), Cellulase (Sigma Aldrich), $\beta$-glucosidase (Sigma Aldrich), 
double distilled water is used in all experiments. AO (NCIM1212) purchased from NCIM, Pune. PS from Indian Institute of Horticulture Research, Bangalore and TH, isolated from Aegle marmelos, courtesy department of Biosciences, SSSIHL.

\subsection{Physicochemical Treatment}

GNS was subjected to physicochemical treatments before being used for production of the cellulolytic enzyme system. GNS was washed thoroughly to remove dirt by repeating the steps such as soaking in water for an hour and filtering. It was then air dried and subsequently in hot air oven at $80^{\circ} \mathrm{C}$ initially to remove the water. The samples were ground and sieved (BSS $25-16$ mesh) to obtain a particle size of $600-1000 \mu \mathrm{m}$. GNS (200 g) was treated in $3000 \mathrm{ml}$ of $1 \%(\mathrm{w} / \mathrm{w})$ $(0.25 \mathrm{M})$ Sodium hydroxide $(\mathrm{NaOH})$ in boiling hot water bath. Biomass was allowed to cool followed by repeated washing in tap water to neutralize $\mathrm{pH}$ and rinsed in distilled water, after which it was air-dried. Pretreated GNS was stored in airtight containers at room temperature until used.

\subsection{Compositional Analysis of GNS}

The composition of the GNS was analysed for extractives, lignin, glucan, xylan, and arabinan content by following the NREL standard protocols. In brief, sample was extracted first with deionized water for $24 \mathrm{~h}$, and then with $95 \%$ ethanol for $24 \mathrm{~h}$ using a Soxhlet Extraction. The sum of water-soluble extractives and acid-soluble extractives was reported as total extractives content of the biomass. The extracted sample was dried in hot-air oven at $45^{\circ} \mathrm{C}$ overnight. The extraction-free sample was hydrolysed using $72 \%(\mathrm{w} / \mathrm{w})$ sulphuric acid at $30^{\circ} \mathrm{C}$ for one hour, followed by dilution of the slurry with DI water to make the acid concentration of $4 \%(\mathrm{w} / \mathrm{w})$ and autoclaved at $121^{\circ} \mathrm{C}$ for 60 minutes. The completely hydrolysed biomass slurry was filtered using a medium porosity porcelain filtering crucible. The filtrate was used to measure glucose, xylose and arabinose content using HPLC, and calculated glucan, xylan and arabinan content. The filtrate was also used to measure acid-soluble lignin content using UV-VIS spectrophotometer. The solid residue in the filtering crucible was first dried in hot-air over at $105^{\circ} \mathrm{C}$ and then in muffle furnace at $575^{\circ} \mathrm{C}$ to measure acid-insoluble lignin. The sum of acid-soluble and acid-insoluble lignin was reported as total lignin content of the biomass [24].

\subsection{Enzyme Assay}

The Mandel and Reese medium used for enzyme production had composition in g/L: Urea, 0.3; $\mathrm{MgSO}_{4} .7 \mathrm{H}_{2} \mathrm{O}, 0.3$; peptone, 0.75; $\mathrm{KH}_{2} \mathrm{PO}_{4}, 2.0 ;\left(\mathrm{NH}_{4}\right)_{2} \mathrm{SO}_{4}, 1.4$; yeast extract, $0.25 ; \mathrm{CaCl}_{2} \cdot 2 \mathrm{H}_{2} \mathrm{O}, 0.4$; and trace elements $(\mathrm{mg} / \mathrm{L}): \mathrm{FeSO}_{4} \cdot 7 \mathrm{H}_{2} \mathrm{O}, 5.0$; $\mathrm{MnSO}_{4} \cdot 7 \mathrm{H}_{2} \mathrm{O}, 1.6 ; \mathrm{ZnSO}_{4} \cdot 7 \mathrm{H}_{2} \mathrm{O}$, 1.4. The extracellular cellulases were extracted by adding $30 \mathrm{ml}$ of citrate buffer $(\mathrm{pH} 5,50 \mathrm{mM})$ to each stationary shake flask in rotary shake incubator (N-Biotek, NB-205V) at $4^{\circ} \mathrm{C}, 60 \mathrm{RPM}$ for 30 minutes. 
The contents were then filtered and analysed for filter paper activity (FPU/gds), CMCase (IU/gds) and $\beta$-glucosidase (IU/gds). Enzymatic assays were carried out using standard protocols as described in Brijwani et al. [9]

\subsection{SSF and SmF}

Three cultures Aspergillus oryzae (AO, NCIM1212, micro fungi), Pycnoporous sanguineus (PS, wood decaying macro fungi) and Trichoderma harzianum (TH, endophytic fungi) were used in this study. Cultures were used as mono, binary $(1: 1)$ and ternary combinations (1:1:1). Pretreated GNS (2 g) was maintained at $70 \%$ moisture content (wet basis) by using Mandel and Reese media [25] of $\mathrm{pH}$ 5.0 and sterilization was done in vertical top load autoclave $\left(121^{\circ} \mathrm{C} / 15 \mathrm{psi}\right.$ gauge) for 20 minutes. Cultures were added as disks with Pasteur pipette for non-sporulating fungi and $10^{8}$ spores/ml suspension for sporulating fungi. The generation, propagation and maintenance of spore suspension are described in our earlier work. The conditions of temperature $\left(30^{\circ} \mathrm{C}\right), \mathrm{pH}$, moisture $(70 \%)$, and incubation days of the SSF process used in this study were optimized in our earlier research [25]. SmF study was performed with same conditions as in SSF with respect to microorganisms used, temperature conditions and incubation period. However, the water content in $\mathrm{SmF}$ is at about $10 \mathrm{ml}$ per $2 \mathrm{~g}$ of biomass along with $5 \mathrm{ml}$ of Mandel and Reese media.

\subsection{Biomass Characterization}

The enzyme treated biomass was washed thoroughly with de-ionised water and sterilized in autoclave for 30 minutes. The residual substrate was oven dried overnight at $80^{\circ} \mathrm{C}$. Physico chemical changes in the biomass substrate were studied using thermal, spectroscopic and surface morphological studies.

\subsubsection{X-Ray Diffraction Studies}

Wide-angle X-ray diffraction (PANalytical, Xpert PRO) was used to estimate the crystallinity of raw and pretreated GNS. The X-rays from a $\mathrm{Cu}$ tube operating at $35 \mathrm{KV}$ and $20 \mathrm{~mA}$ were collected by an energy dispersive detector that is able to resolve $\mathrm{CuKa}$ line. Counts were collected at a step size of $0.02^{\circ}$ at a series of angles between $10^{\circ}$ and $50^{\circ}$. Speed of count collection was $0.6^{\circ} /$ minute.

\subsubsection{Thermogravimetric Analysis (TGA)}

The structural rigidity changes in the GNS substrate were probed using TGA of raw, alkali treated and fungal treated biomass. The biomass was tested in TGA (METTLER TOLEDO TGA/DSC1) at the rate of $0.5^{\circ} \mathrm{C}$ per sec. between temperature range of $30^{\circ} \mathrm{C}-1000^{\circ} \mathrm{C}$. The samples were weighed to about $5 \mathrm{mg}$ and loaded into alumina pan with a nitrogen flow of $10 \mathrm{ml}$ per minute. DSC provides the heat flow information ( $\mathrm{mW}$ ) and TGA the percentage weight loss (mg).

\subsubsection{FT-IR Analysis}

The samples were dried, ground and incorporated into $\mathrm{KBr}(\sim 3 \mathrm{mg}$ in $75 \mathrm{mg})$ using hand press. The infrared spectrum measured from $4000-400 \mathrm{~cm}^{-1}$ was 
obtained using THERMO SCIENTIFIC, NICOLET iS10 model by measuring 32 scans. The changes in the functional group pattern was studied by measuring the spectra and compared across all the enzyme treated substrates, reflected in the pretreated and the fungal treated biomass.

\subsubsection{SEM Imaging}

The morphology of GNS before and after the chemical and fungal treatment was studied with scanning electron microscope (SEM, LEO $1530 \mathrm{VP}$ ). The modifications of the morphology were studied by taking images at several magnifications of both chemical and fungal treated GNS. The samples were made conductive by sputtering with gold and observed using a $5 \mathrm{kV}$ voltage source.

\section{Results and Discussion}

\subsection{Effect of Individual and Mixed Cultures on Enzyme Production}

Under both SSF and SmF conditions, there is a continuous increase in FPU and CMCase until $6^{\text {th }}$ day; increase in $\beta$-glucosidase until the $4^{\text {th }}$ day, for all the culture combinations undertaken in this study. After the $6^{\text {th }}$ and $4^{\text {th }}$ day, the activity either stayed stable or declined, respectively. The authors had observed a similar trend in their previous study involving cellulase production from biomass under SSF and SmF conditions for individual and binary cultures [26]. The reason behind this trend could be attributed to the exhausting of available monosaccharide sugars, which are released by fungi during saccharification of oligosaccharides derived from cellulose. Decline of these sugars, especially glucose will signal the fungi to release more hydrolytic enzymes resulting in more sugars formation; however, the time interval at which the optimum enzyme activity occurs for these different classes of enzymes varies. This cycle would continue until all the sugars are consumed completely.

This explains why we observe rise in enzyme activity on $6^{\text {th }}$ day and again on $10^{\text {th }}$ day for CMCase and $\beta$-glucosidase. Cellulase (FPU/gds), CMCase (IU/gds) and $\beta$-glucosidase (IU/gds) of $40.5 \pm 4.84,192.8 \pm 8.1$ and $177.3 \pm 6.9$ are produced respectively for mono-culture $(\mathrm{AO})$ on $2^{\text {nd }}$ day which is higher than reported [27]. Cellulase, CMCase and $\beta$-glucosidase activity in the range 74.0 154.2 (FPU/gds), 180.9 - 471.5 (IU/gds), and 180.6 - 956.6 (IU/gds), respectively, for combination of cultures in 6 - 10 days were observed in SSF (Figure 1). With mixed fungal cultures, we observed higher productivity over individual cultures. Earlier studies on agro wastes also established that mixed cultures ( $A$. niger and T. reesei) exhibit synergism over mono cultures in SSF conditions [28].

Cellulase activity: In SSF condition (Figure 1(a)), highest activity of $154.2 \pm$ 1.6 FPU/gds and $123.8 \pm 3.7 \mathrm{FPU} / \mathrm{gds}$ was observed on the $6^{\text {th }}$ day for AO $+\mathrm{PS}$ and $\mathrm{AO}+\mathrm{PS}+\mathrm{TH}$ combinations respectively. In SmF conditions (Figure 1(b)), highest activity of $154.27 \pm 4.7 \mathrm{FPU} / \mathrm{gds}$ and $139.05 \pm 11.8 \mathrm{FPU} / \mathrm{gds}$ was observed on the $6^{\text {th }}$ day for AO + PS combination and monoculture of PS, respectively. 

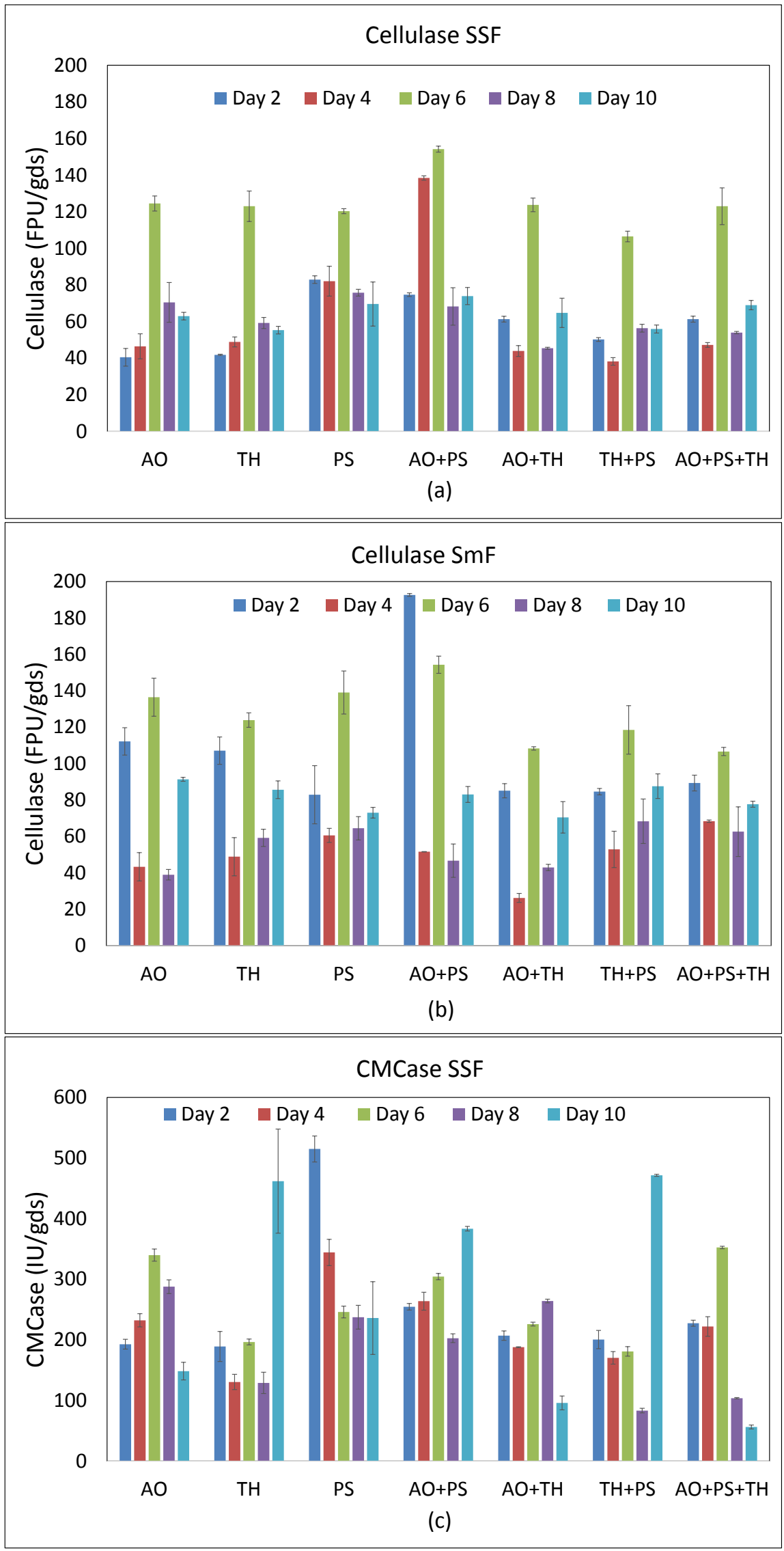

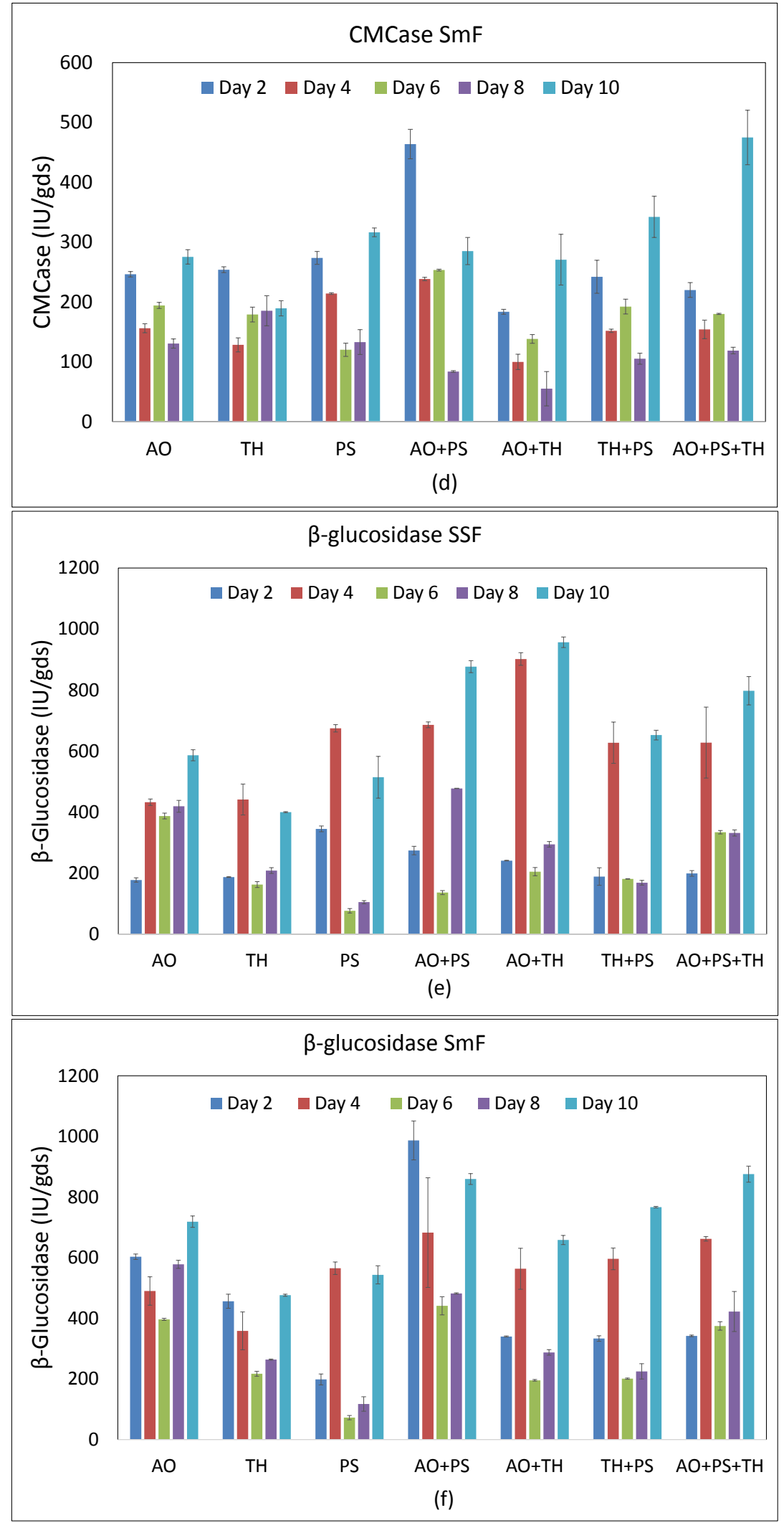

Figure 1. Quantification of enzyme activity of combinations of AO, PS and TH: Cellulase-(a) SSF; (b) SmF; CMCase-(c) SSF; (d) SmF and $\beta$-glucosidase-(e) SSF; (f) SmF. 
CMCase activity: The increase in CMCase activity was significant on $6^{\text {th }}$ day for SSF across mono and combination of cultures whereas independent PS released greater amounts of CMCase on $2^{\text {nd }}$ day that decreased gradually on $10^{\text {th }}$ day. The CMC activity of SSF (Figure $1(\mathrm{c})$ ) for ternary combination of AO + PS $+\mathrm{TH}$ was maximum on $6^{\text {th }}$ day at $352.4 \pm 2.1 \mathrm{IU} / \mathrm{gds}$; and $10^{\text {th }}$ day at $471.5 \pm 1.7$ IU/gds for TH + PS. In SmF conditions (Figure 1(d)), the activity was only $179.9 \pm 1.0 \mathrm{IU} / \mathrm{gds}\left(6^{\text {th }}\right.$ day) for ternary combination of $\mathrm{AO}+\mathrm{PS}+\mathrm{TH}$ and $342.12 \pm 34.5 \mathrm{IU} / g d s$ for $\mathrm{TH}+$ PS suggesting that SSF conditions are more favourable over SmF conditions. The reason could be the presence of glucose in fermentation medium in higher concentration thus causing catabolic repression. Although CMCase activity declined for PS after 48 hours, an increase in CMCase was observed in combination with $\mathrm{AO}$ and ternary combination of $\mathrm{AO}$ and $\mathrm{TH}$. The increase was significant for ternary combination of fungi on $6^{\text {th }}$ day compared to other mono cultures.

$\beta$-glucosidase activity: $\beta$-glucosidase production was maximum on $4^{\text {th }}$ day for all the combinations of fungi for both SSF and SmF conditions. Highest value of $797.6 \pm 46.5 \mathrm{IU} / \mathrm{gds}$ and $876.7 \pm 19.8 \mathrm{IU} / \mathrm{gds}$ was observed for $10^{\text {th }}$ day in $\mathrm{AO}+$ $\mathrm{PS}+\mathrm{TH}$ and $\mathrm{AO}+\mathrm{PS}$ combination, respectively, in SSF condition (Figure 1(e)). In SmF condition (Figure 1(f)), $875.63 \pm 26.4 \mathrm{IU} / \mathrm{gds}$ and $987.0 \pm 64.2$ IU/gds was observed for $\mathrm{AO}+\mathrm{PS}+\mathrm{TH}$ and $\mathrm{AO}+\mathrm{PS}$ combination, respectively; suggesting that $\beta$-glucosidase production is promising in both SSF and SmF conditions.

From our studies (Table 1), we can deduce that to attain high activity of cellulase enzyme a ternary combination of $\mathrm{AO}+\mathrm{PS}+\mathrm{TH}$ cultures under SmF condition is conducive, whereas, monoculture of $\mathrm{PO}$ gave high activity of CMCase under SSF condition. Further, binary combination of AO + PS under SmF condition provided very high $\beta$-glucosidase activity. Our promising approach for targeted enzymes production is summarized in Table 1 . Thus, we can conclude that depending on the particular class of enzyme required for production, an appropriate combination of fungal consortia and the method of fermentation will provide the desired high activity.

\subsection{Characterization}

\subsubsection{Biomass Composition}

Table 2 showed that the groundnut biomass had around 40\% lignin content, which is almost equal to the total carbohydrate content in the biomass. Typically, lignin content of groundnut shell is around $26.4 \%$ as reported by Patricia et al. [29]. However, the plant lignin content is significantly affected by its genotype as well as the environment in which the plant is cultivated [30]. Boonmee reported $35.2 \%$ lignin content in peanut shell [31], which is in close agreement with our reported values. This clearly shows that some cultivars of GNS grown at specific agronomic environment could have higher lignin content, and hence it is important to consider the lignin content while designing fermentation procedure to generate value-added products. 
Table 1. Combination of fungal cultures for efficient enzyme production on GNS.

\begin{tabular}{cccc}
\hline Enzyme & Activity & Consortia & Mode \\
\hline Cellulase & $154.2 \pm 1.63 \mathrm{FPU} / \mathrm{gds}$ & $\mathrm{AO}+\mathrm{PS}$ & $\mathrm{SmF}$ \\
CMCase & $514.97 \pm 21.4 \mathrm{IU} / \mathrm{gds}$ & $\mathrm{PS}$ & $\mathrm{SSF}$ \\
$\beta$-glucosidase & $875.63 \pm 1.68 \mathrm{IU} / \mathrm{gds}$ & $\mathrm{AO}+\mathrm{PS}+\mathrm{TH}$ & $\mathrm{SmF}$ \\
\hline
\end{tabular}

Table 2. Composition of groundnut shell biomass.

\begin{tabular}{ccc}
\hline $\begin{array}{c}\text { Biomass } \\
\text { Component }\end{array}$ & Composition of alkali extracted biomass & Composition of raw biomass \\
\hline Glucan (\%) & $29.80 \pm 0.36$ & $24.70 \pm 0.48$ \\
Xylan (\%) & $13.25 \pm 0.75$ & $13.47 \pm 0.36$ \\
Arabinan (\%) & $0.91 \pm 0.03$ & $2.0 \pm 0.14$ \\
Lignin (\%) & $39.80 \pm 0.47$ & $41.74 \pm 0.49$ \\
Extractives (\%) & $3.80 \pm 0.12$ & $5.91 \pm 0.63$ \\
\hline
\end{tabular}

In our subsequent experiments, the milder alkali pretreatment did not generate sufficient sugars with concomitant poor ethanol yield (results not included). However, the pretreated biomass was a promising feedstock to produce cellulolytic enzymes system as shown in our results. Table 2 shows the detailed composition of GNS before and after alkali pretreatment.

\subsubsection{Effect of Enzyme Treatment on Cellulose Crystallinity}

Biomass constituted of amorphous and crystalline components. Hemicellulose and lignin are amorphous in nature. Cellulose contains both amorphous and crystalline allomorphs such as para-crystalline cellulose and crystalline cellulose allomorphs (cellulose $I_{\alpha}$ and cellulose $I_{\beta}$ ). Crystallinity of cellulose is an important parameter because material properties depend on crystal lattice structure, crystallite dimensions and crystallinity. Studies to track the ultrastructural changes of cellulose [32], observed depletion of allomorphs of cellulose during enzymatic hydrolysis with cellulase. Enzymatic deconstruction of cellulose follows the trend of rapid depletion of para-crystalline and amorphous cellulose, followed by cellulose $I_{\alpha}$ and cellulose $I_{\beta}$. This study suggests that cellulose crystallinity along with crystal lattice structure affect enzymatic hydrolysis and thus biomass recalcitrance. The powder X-ray Diffraction pattern of untreated, alkali treated and enzyme treated are presented in Figure 2. There are three broad peaks at $16.2^{\circ}, 22.1^{\circ}$ and $34.7^{\circ}$ for enzyme treated GNS which is consistent with cellulose I lattice. The fraction of cellulose crystallinity was calculated using the following equation:

$$
C r I=\frac{I_{\text {total }}-I_{\text {am }}}{I_{\text {total }}} \times 100
$$

where $C r I$ is the Crystallinity Index, $I_{\text {total }}$ is intensity of the (002) peak at $22.4^{\circ}$ and $I_{\mathrm{am}}$ is the minimal depression of amorphous structure (intensity of the background scatter at $18.7^{\circ}$ ) [33]. 


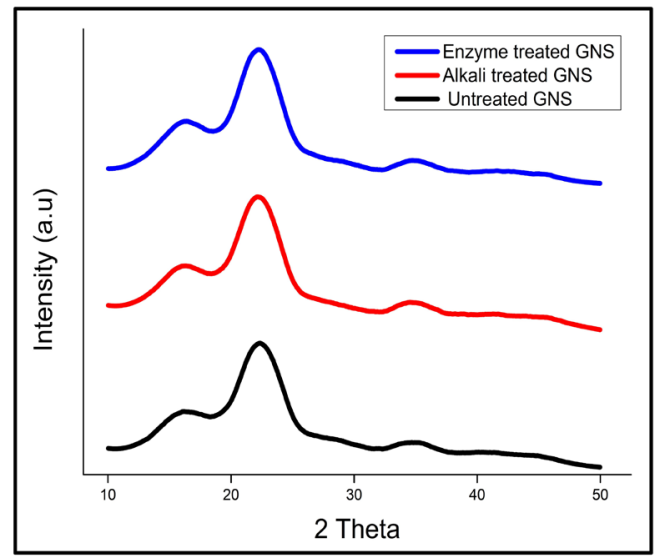

Figure 2. Powder XRD patterns of GNS: untreated, alkali treated and enzyme treated.

Treatment of GNS with alkali, influenced the crystallinity due to change in biomass composition. The raw biomass displayed lower value of $37.4 \%$ because it contains larger amounts of hemicellulose and lignin in corroboration with our biomass composition study in Table 3. CrI changed to $40.0 \%$ from $37.4 \%$ after alkali treatment because of removal of hemicellulose and lignin by the action of $\mathrm{NaOH}$ as shown in Table 3. The crystallinity index of fungal treated biomass turned out to be larger than the alkali treated and also varied from mono cultures to ternary cultures as shown in Table 3. Ganguly et al. observed that the fungal treatment affects amorphous cellulose more than the crystalline fragment of cellulose [34]. We conclude that the combinations of cultures have diverse effects on the composition of biomass depending on the enzymes released and treatment conditions.

\subsection{FT-IR Analysis}

The FT-IR spectra of GNS samples indicated chemical changes in the biomass upon pretreatment and enzyme saccharification. Variation in the absorbance values provided understanding of changes in biomass substrate composition and partial removal of lignin. Absorbance values of the analysed peaks displayed a close trend of variation, which corresponds to the cellulose, hemicellulose and lignin content as shown by a vertical line in Figure 3 whose corresponding peaks assigned to functional groups are displayed in Table 4. The glycosidic linkage in hemicelluloses and lignin display a peak at $850 \mathrm{~cm}^{-1}$ while the $917 \mathrm{~cm}^{-1}$ peak was attributed to cellulose, hemicellulose and lignin's glycosidic linkage. C-O valence vibration of cellulose displays a peak at $993 \mathrm{~cm}^{-1}$. Peak at $1072 \mathrm{~cm}^{-1}$ is due to glycosidic linkage $\mathrm{C}-\mathrm{O}, \mathrm{C}-\mathrm{C}-\mathrm{O}$ stretching of three polymers.

Asymmetric stretching of C-O-C in cellulose and hemicellulose could possibly result as peak at $1111 \mathrm{~cm}^{-1}$. Intense peak at $1220 \mathrm{~cm}^{-1}$ is due to $\mathrm{C}-\mathrm{O}$ stretch in lignin due to alcohol groups. Syringyl ring of lignin displays a peak at $1322 \mathrm{~cm}^{-1}$ due to $\mathrm{C}-\mathrm{O}$ stretch clearly demonstrates decrease in lignin content from untreated GNS. Cellulose and hemicellulose in GNS showed an intense peak at 
$1400 \mathrm{~cm}^{-1}$ and $1384 \mathrm{~cm}^{-1}$ due to aliphatic C-H band. Dominant peak at 1590 $\mathrm{cm}^{-1}$ is attributed to aromatic ring $\mathrm{C}=\mathrm{C}$ stretch of lignin which changed after alkali treatment due to removal of lignin. The broad absorbance peak in 3400 $3000 \mathrm{~cm}^{-1}$ is due to surface hydroxyl groups stretching vibration and increased remarkably after alkali treatment indicating the exposure of cellulose and hemicellulose. Summary of functional groups present in the biomass and the corresponding absorbance values are given in Table 4 . In our previous study, we observed that changes in the functional group intensities of the biomass help in comprehending the structural variation of biopolymers [35].

Table 3. Degree of crystallinity of fungal treated GNS in SSF conditions on $10^{\text {th }}$ day.

\begin{tabular}{cc}
\hline Enzyme treated GNS & Degree of crystallinity \\
\hline Untreated GNS & 37.4 \\
Alkali treated GNS & 40.0 \\
AO & 54.0 \\
TH & 55.2 \\
PS & 49.2 \\
AO+PS & 49.7 \\
AO+TH & 51.0 \\
PS+TH & 49.1 \\
AO+PS+TH & 51.3 \\
\hline
\end{tabular}

Table 4. FT-IR spectral analysis of the enzyme treated biomass and peak assignments.

\begin{tabular}{|c|c|c|c|}
\hline $\begin{array}{l}\text { Wave numbers } \\
\qquad\left(\mathrm{cm}^{-1}\right)\end{array}$ & Assignment & Polymer & References \\
\hline 875 & Glycosidic linkage & Hemicellulose & \\
\hline 930 & Glycosidic linkage & Cellulose, Hemicellulose, Lignin & \\
\hline 990 & $\mathrm{C}-\mathrm{O}$ valence vibration & Cellulose & [26] \\
\hline 1035 & $\begin{array}{c}\mathrm{C}-\mathrm{O}, \mathrm{C}=\mathrm{C}, \mathrm{C}-\mathrm{C}-\mathrm{O} \text { vibrational } \\
\text { stretching }\end{array}$ & Cellulose, Hemicellulose, Lignin & \\
\hline 1160 & $\mathrm{C}-\mathrm{O}-\mathrm{C}$ asymmetrical stretching & Cellulose, Hemicellulose & \\
\hline 1215 & $\mathrm{C}-\mathrm{C}+\mathrm{C}-\mathrm{O}$ stretching & Lignin & \\
\hline 1327 & $\mathrm{C}-\mathrm{O}$ of syringyl ring & Lignin & {$[33]$} \\
\hline 1335 & \multicolumn{2}{|c|}{$\mathrm{C}-\mathrm{H}$ bending, $\mathrm{O}-\mathrm{H}$ in-plane bendingCellulose, Hemicellulose, Lignin } & \\
\hline 1380 & C-H bending & Cellulose, Hemicellulose, Lignin & \\
\hline 1440 & $\mathrm{O}-\mathrm{H}$ in-plane bending & Cellulose, Hemicellulose, Lignin & \\
\hline 1595 & Aromatic ring $\mathrm{C}=\mathrm{C}$ vibration & Lignin & [35] \\
\hline 3343 & -OH stretching & Cellulose, Hemicellulose, Lignin & \\
\hline
\end{tabular}




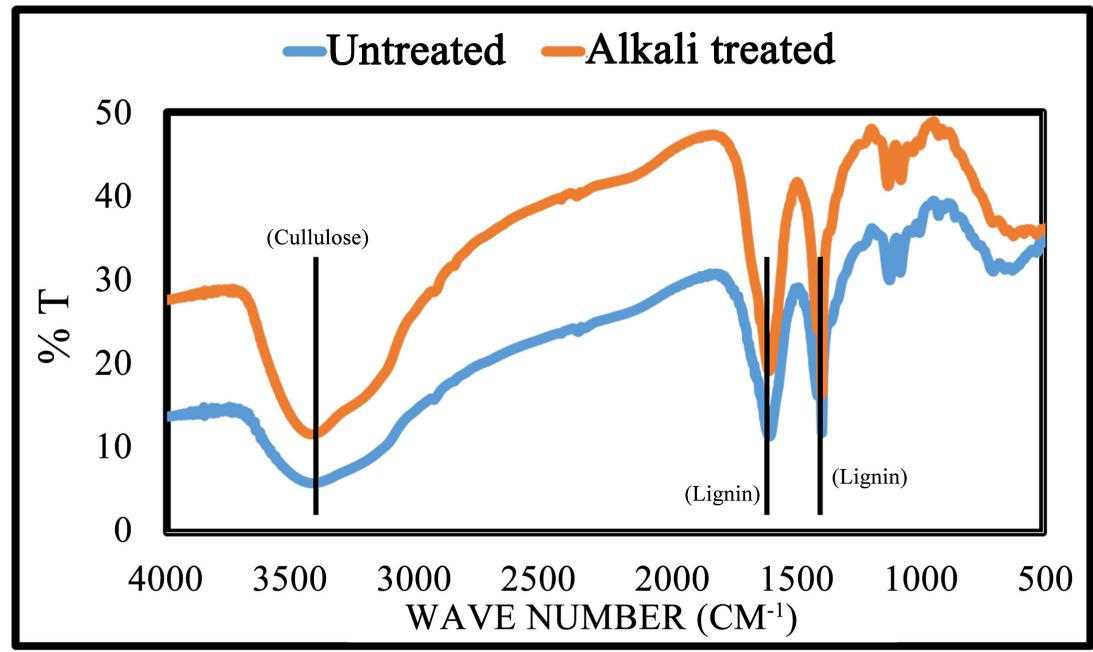

(a)

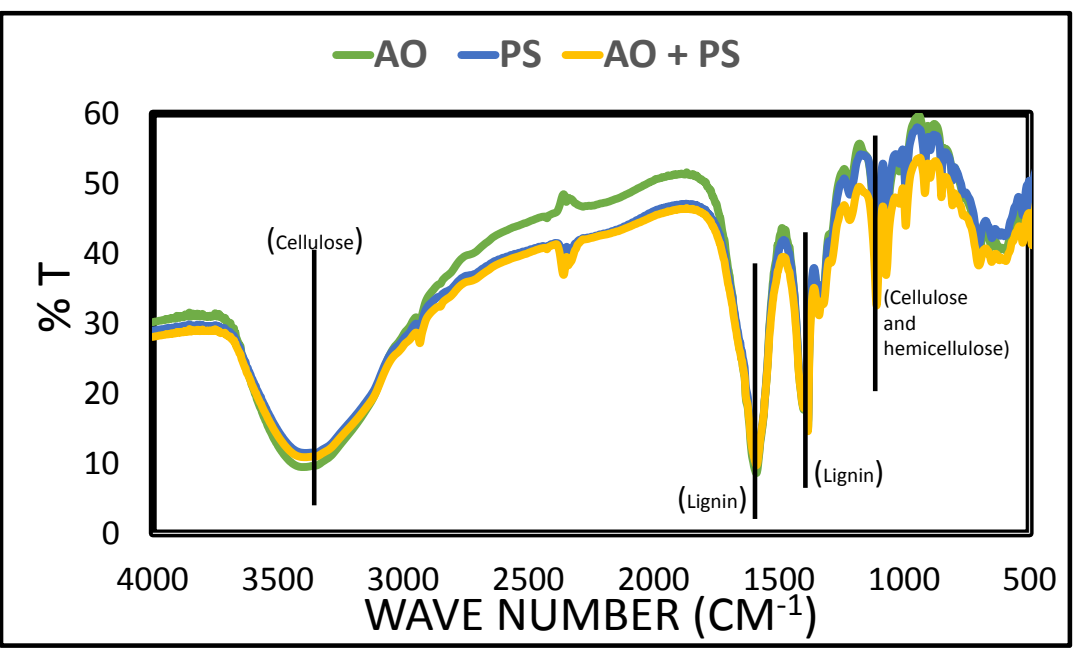

(b)

Figure 3. FT-IR of the (a) untreated GNS and alkali treated GNS; (b) AO, PS, AO + PS combinations respectively.

\subsection{Thermogravimetric Analysis (TGA)}

TGA analysis of the raw, alkali-treated and fungal-treated substrates was performed to test their thermal decomposition. Thermogravimetry curve which records weight change of the biomass as a function of temperature i.e., the thermal behaviour of biomass on pyrolysis. First derivative of TGA known as differential thermogravimetry curve (DTG) gives the rate at which the reaction is undergoing. The DTG thermogram in Figure 4 revealed prominently three peaks in the exothermic regions in agreement with previous studies [26].

Degradation of GNS happened in three stages. In stage one, at around $85^{\circ} \mathrm{C}$ $120^{\circ} \mathrm{C}$ in which, bound water desorption occurs along with weakening of hydrogen bonds between the carbohydrates [36]. In stage two, degradation occurs around $200^{\circ} \mathrm{C}-350^{\circ} \mathrm{C}$ where decomposition of low volatile carbohydrates such as cellulose and hemicellulose is observed. Hemicellulose starts to decompose 
earlier due to its linear polymer chain structure and short side chains and at about $325^{\circ} \mathrm{C}$, relatively more stable crystalline cellulose starts to degrade between $325^{\circ} \mathrm{C}-400^{\circ} \mathrm{C}$.

In Figure 4(a), raw GNS contain great amounts of lignin covering the cellulose and hemicellulose, whereas alkali treatment disrupts the lignin bonding with holocellulose. It is observed in Figure 4(b) where the exposed cellulose is resulting in a peak corresponding to cellulose degradation. In Figure 4(c), the effect of fungal treatment is observed with the loss of cellulose peak due to the action of cellulases on the alkali treated GNS. In stage three, above $400^{\circ} \mathrm{C}$, reveals higher volatiles degradation such as lignin which is relatively more stable than cellulose and hemicellulose. The process displays exothermic effect till $735^{\circ} \mathrm{C}$, corresponding to the char aggregation and the heat produced is the result of the degradation of biomass [37]. This is in correlation with the data reflected in biomass composition (Table 2) and XRD data.

\subsection{SEM Imaging}

Microbe fortified biomass consisting of the various combinations of fungal cultures in both SSF and SmF conditions were analyzed for surface morphological changes using SEM. Untreated GNS display high roughness with hollow cavities and after alkali treatment the surface smoothened indicating deconstruction of lignocellulosic linkages in Figure 5. A \& B thereby suggesting that the cellulosic fibers are more exposed.

Further on enzymatic treatment with binary $(\mathrm{AO}+\mathrm{PS})$ and ternary cultures $(\mathrm{AO}+\mathrm{PS}+\mathrm{TH})$ it was observed that the texture exhibited more porosity indicating bioconversion of cellulosic fibres as observed in Figure 5(c) and Figure 5(d). During alkali treatment, the cell walls collapses and the fibres are detached along with formation of pores, which is evident in $\mathrm{AO}+\mathrm{PS}+\mathrm{TH}$ combination of Figure 5(e). In ternary culture of GNS with AO + PS + TH Figure 5(f), the result of enzymatic action on GNS disturbed the integrity of surface, forming pronounced pits on the surface; thereby indicating that the ternary consortia was more efficient in the systemic breakdown of the heteropolymers present in the biomass.

Cellulase and CMCase production improved significantly till $6^{\text {th }}$ day in mixed culture fermentation whereas $\beta$-glucosidase production was produced in greater quantities. The alteration in the physico-chemical attributes in biomass composition due to alkali treatment and enzyme treatment was thoroughly studied using characterization techniques and found to be culture specific. The FT-IR spectroscopy along with X-ray crystallography studies of alkali treated and enzyme treated substrates established the changes in nature of holocelluloses. DSC and TGA revealed the changes in the structural integrity of biomass.

\section{Conclusions}

Effective hydrolysis of cellulose present in biomass requires a synergistic action 
of three different classes of enzymes. Presence of microbial consortia for enzymatic hydrolysis will undoubtedly lead to the generation of these classes of enzymes.

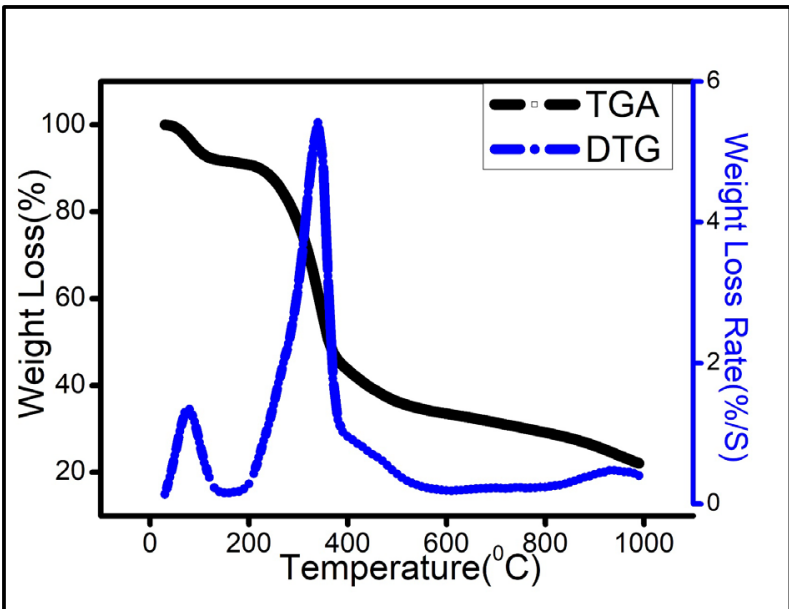

(a)

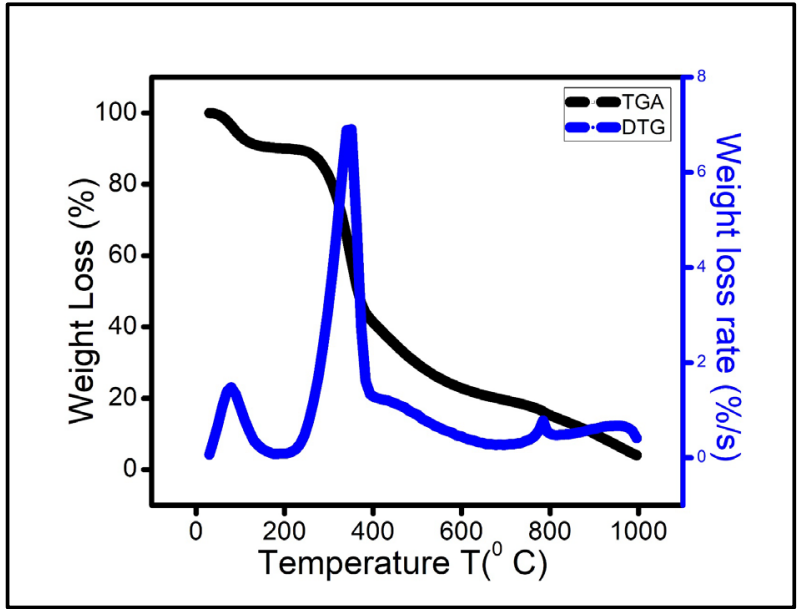

(b)

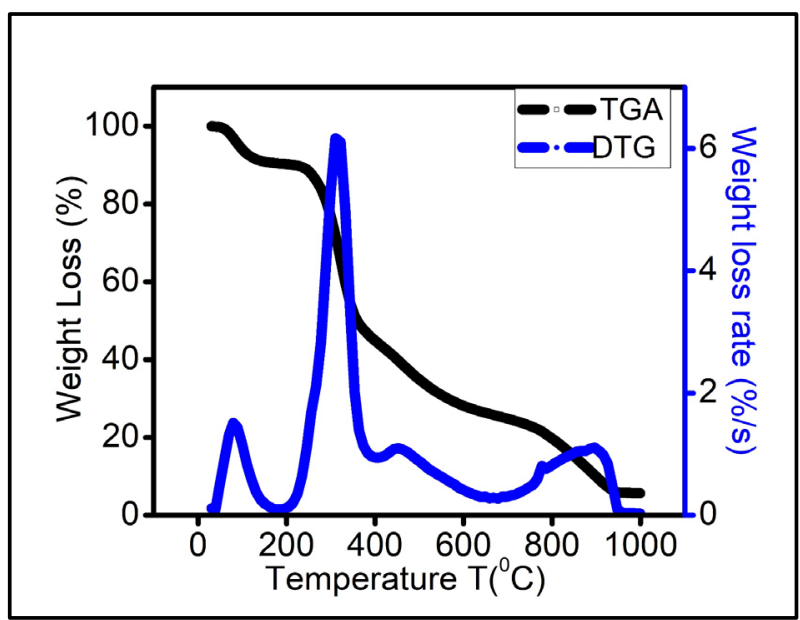

(c)

Figure 4. TGA graphs of effect of thermal behaviour of GNS (a) raw, (b) alkali treated and (c) fungal treated. 

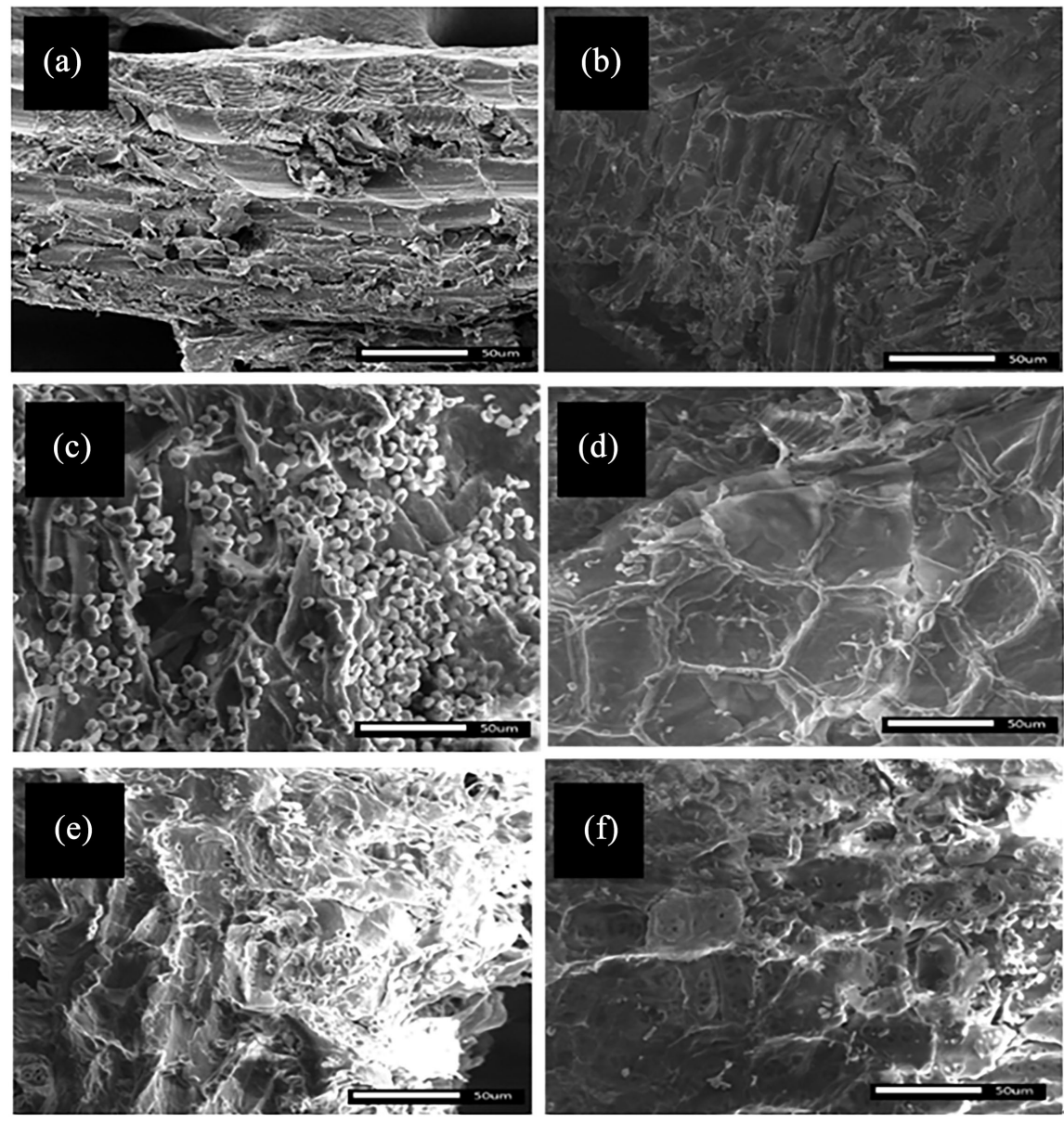

Figure 5. (a) Untreated GNS (b) Alkali treated GNS, AO + PS in (c) SSF and (d) SLF, $\mathrm{AO}+\mathrm{PS}+\mathrm{TH}$ in (e) SSF and (f) SLF.

To the best of our knowledge, current work demonstrated for the first time, the synergistic effect of enzymes production from ternary cultures of $A$. oryzae (epiphytic fungus), T. harzianum (endophytic fungus) and $P$. sanguineus (macro fungi) with significant amount of enzymes production from GNS. In nature, the saprophytic fungal cultures work as a synergistic consortium to efficiently decompose dead biomass; in our innovative study we carefully selected ternary cultures that will act in tandem and deliver the desired enzymes system of importance for bioconversion. We also conclude that the interplay of the combination of cultures, fermentation system and duration of the experiments has a pronounced effect on the individual class of enzyme activity, which suggests that we must pick the appropriate combination of cultures and operation mode if our interest is specific to an enzyme.

The alteration in the physico-chemical attributes in biomass composition due to alkali treatment and enzyme treatment was thoroughly studied using characterization techniques and was found to be culture specific. The FT-IR spectroscopy along with XRD studies of alkali treated and enzyme treated substrates provide molecular level understanding of delignification upon alkali and enzy- 
matic treatment, respectively. DSC revealed that degradation of GNS happened in three stages namely via water removal followed by cellulose, hemicellulose and lignin deconstruction; crucial for understanding the structural integrity of biomass.

As per the above study, the following recommendations can be made:

1) Before the utilization of any specific biomass feedstock for value-addition, it is imperative to determine the compositional analysis of the feedstock; based on the sugars and lignin content an effective bioconversion strategy can be optimized for a targeted product.

2) The characterization of the substrate before, during, and after the bioprocessing is a rationale tool for process analysis and provides a framework for the better design of the sequential enzymatic degradation to sugars followed by fermentation process to biofuels and other products.

3) Further, the structural analysis of the biomass residue will enable its appropriate utilization for potential high-valued carbon materials such as carbon dots [38] and supercapacitors for renewable energy applications.

4) In addition to cellulase enzyme production, judicious selection of microbial consortia is required to generate hemicellulolytic and ligninolytic enzyme systems for complete utilization of all the three polymers present in biomass for sustainable value addition.

5) It makes more economic sense to pursue multiple products from the same feedstock and accordingly develop an integrated process to realize this goal.

\section{Acknowledgements}

We are indebted to Bhagawan Sri SathyaSai Baba the Founding Chancellor, SSSIHL for his vision and inspiration to serve the society. We are thankful to the administration and the Central Research Instruments Facility (CRIF), SSSIHL for providing the various resources in the relevant studies. SSR acknowledges the funding from DBT-Ramalingaswami fellowship (Sanction Order No. 102/IFD/ SAN/776/2015-16), Govt. of India. The authors are grateful to Dr. Murali Krishna Molli and Mr. Sandeep Patnaik, Department of Physics, for helping with XRD and DSC instrumentation. The authors are grateful to Dr. Robin Sharma, Department of Biosciences, SSSIHL, for providing Trichoderma harzianum culture for our studies.

\section{Conflicts of Interest}

The authors declare no conflicts of interest regarding the publication of this paper.

\section{References}

[1] Srilekha Yadav, K., Naseeruddin, S., Sai Prashanthi, G., Sateesh, L. and Venkateswar Rao, L. (2011) Bioethanol Fermentation of Concentrated Rice Straw Hydrolysate Using Co-Culture of Saccharomyces cerevisiae and Pichia stipitis. Bioresour. Technol., 102, 6473-6478. https://doi.org/10.1016/j.biortech.2011.03.019 
[2] Yasmeen, Q., Asgher, M., Sheikh, M.A. and Nawaz, H. (2013) Optimization of Ligninolytic Enzymes Production through Response Surface Methodology. BioResources, 8, No. 1 .

http://ojs.cnr.ncsu.edu/index.php/BioRes/article/view/BioRes_08_1_944_Yasmeen Ligninolytic_Enzymes_Production

[3] Shah, S.H., Raja, I.A., Rizwan, M., Rashid, N., Mahmood, Q., Shah, F.A. and Pervez, A. (2018) Potential of Microalgal Biodiesel Production and Its Sustainability Perspectives in Pakistan. Renewable and Sustainable Energy Reviews, 81, 76-92. https://doi.org/10.1016/j.rser.2017.07.044

[4] Bubner, P., Plank, H. and Nidetzky, B. (2013) Visualizing Cellulase Activity. Biotechnology and Bioengineering, 110, 1529-1549. https://doi.org/10.1002/bit.24884

[5] Bischoff, K.M., Wicklow, D.T., Jordan, D.B., de Rezende, S.T., Liu, S., Hughes, S.R. and Rich, J.O. (2009) Extracellular Hemicellulolytic Enzymes from the Maize Endophyte Acremonium zeae. Current Microbiology, 58, 499-503.

https://doi.org/10.1007/s00284-008-9353-Z

[6] Yang, P., Guo, L., Cheng, S., Lou, N. and Lin, J. (2011) Recombinant Multi-Functional Cellulase Activity in Submerged Fermentation of Lignocellulosic Wastes. Renewable Energy, 36, 3268-3272. https://doi.org/10.1016/j.renene.2011.04.019

[7] Bañuelos, J.A., Velázquez-Hernández, I., Guerra-Balcázar, M. and Arjona, N. (2018) Production, Characterization and Evaluation of the Energetic Capability of Bioethanol from Salicornia Bigelovii as a Renewable Energy Source. Renewable Energy, 123, 125-134. https://doi.org/10.1016/j.renene.2018.02.031

[8] Gyalai-Korpos, M., Mangel, R., Alvira, P., Dienes, D., Ballesteros, M. andRéczey, K. (2010) Cellulase Production Using Different Streams of Wheat Grain- and Wheat Straw-Based Ethanol Processes. Journal of Industrial Microbiology \& Biotechnology, 38, 791-802. https://doi.org/10.1007/s10295-010-0811-9

[9] Brijwani, K., Oberoi, H.S. and Vadlani, P.V. (2010) Production of a Cellulolytic Enzyme System in Mixed-Culture Solid-State Fermentation of Soybean Hulls Supplemented with Wheat Bran. Process Biochemistry, 45, 120-128.

https://doi.org/10.1016/j.procbio.2009.08.015

[10] Oberoi, H.S., Vadlani, P.V., Brijwani, K., Bhargav, V.K. and Patil, R.T. (2010) Enhanced Ethanol Production via Fermentation of Rice Straw with Hydrolysate-Adapted Candida tropicalis ATCC 13803. Process Biochemistry, 45, 1299-1306. https://doi.org/10.1016/j.procbio.2010.04.017

[11] Zhao, C., Zou, Z., Li, J., Jia, H., Liesche, J., Chen, S. and Fang, H. (2018) Efficient Bioethanol Production from Sodium Hydroxide Pretreated Corn Stover and Rice Straw in the Context of On-Site Cellulase Production. Renewable Energy, 118, 14-24. https://doi.org/10.1016/j.renene.2017.11.001

[12] Oberoi, H.S., Vadlani, P.V., Nanjundaswamy, A., Bansal, S., Singh, S., Kaur, S. and Babbar, N. (2011) Enhanced Ethanol Production from Kinnow Mandarin (Citrus reticulata) Waste via a Statistically Optimized Simultaneous Saccharification and Fermentation Process. Bioresource Technology, 102, 1593-1601. https://doi.org/10.1016/j.biortech.2010.08.111

[13] Media Today Group, SAARC Oils and Fats Today, Media Today Gr. 4. http://oilsfatstoday.com/news_articles.php

[14] Amore, A., Parameswaran, B., Kumar, R., Birolo, L., Vinciguerra, R., Marcolongo, L., Ionata, E., La Cara, F., Pandey, A. and Faraco, V. (2014) Application of a New Xylanase Activity from Bacillus amyloliquefaciens XR44A in Brewer's Spent Grain Saccharification. Journal of Chemical Technology \& Biotechnology, 90, 573-581. https://doi.org/10.1002/jctb.4589 
[15] Wei, H., Tucker, M.P., Baker, J.O., Harris, M., Luo, Y., Xu, Q., Himmel, M.E. and Ding, S.-Y. (2012) Tracking Dynamics of Plant Biomass Composting by Changes in Substrate Structure, Microbial Community, and Enzyme Activity. Biotechnology for Biofuels, 5, 20. https://doi.org/10.1186/1754-6834-5-20

[16] Yamada, R., Taniguchi, N., Tanaka, T., Ogino, C., Fukuda, H. and Kondo, A. (2010) Cocktail $\delta$-Integration: A Novel Method to Construct Cellulolytic Enzyme Expression Ratio-Optimized Yeast Strains. Microbial Cell Factories, 9, 32. https://doi.org/10.1186/1475-2859-9-32

[17] Treebupachatsakul, T., Nakazawa, H., Shinbo, H., Fujikawa, H., Nagaiwa, A., Ochiai, N., Kawaguchi, T., Nikaido, M., Totani, K., Shioya, K., Shida, Y., Morikawa, Y., Ogasawara, W. and Okada, H. (2016) Heterologously Expressed Aspergillus aculeatus $\beta$-Glucosidase in Saccharomyces cerevisiae Is a Cost-Effective Alternative to Commercial Supplementation of $\beta$-Glucosidase in Industrial Ethanol Production Using Trichoderma reesei Cellulases. Journal of Bioscience and Bioengineering, 121, 27-35. https://doi.org/10.1016/j.jbiosc.2015.05.002

[18] Fang, H., Zhao, C. and Song, X.-Y. (2010) Optimization of Enzymatic Hydrolysis of Steam-Exploded Corn Stover by Two Approaches: Response Surface Methodology or Using Cellulase from Mixed Cultures of Trichoderma reesei RUT-C30 and Aspergillus niger NL02. Bioresource Technology, 101, 4111-4119.

https://doi.org/10.1016/j.biortech.2010.01.078

[19] Dotsenko, G.S., Gusakov, A.V., Rozhkova, A.M., Korotkova, O.G. and Sinitsyn, A.P. (2015) Heterologous $\beta$-Glucosidase in a Fungal Cellulase System: Comparison of Different Methods for Development of Multienzyme Cocktails. Process Biochemistry, 50, 1258-1263. https://doi.org/10.1016/j.procbio.2015.05.008

[20] Lu, J., Weerasiri, R.R., Liu, Y., Wang, W., Ji, S. and Lee, I. (2013) Enzyme Production by the Mixed Fungal Culture with Nano-Shear Pretreated Biomass and Lignocellulose Hydrolysis. Biotechnology and Bioengineering, 110, 2123-2130. https://doi.org/10.1002/bit.24883

[21] Fan, Z., Wu, W., Hildebrand, A., Kasuga, T., Zhang, R. and Xiong, X. (2012) A Novel Biochemical Route for Fuels and Chemicals Production from Cellulosic Biomass. PLoS ONE, 7, e31693. https://doi.org/10.1371/journal.pone.0031693

[22] Sigoillot, C., Lomascolo, A., Record, E., Robert, J., Asther, M. and Sigoillot, J. (2002) Lignocellulolytic and Hemicellulolytic System of Pycnoporus cinnabarinus. Isolation and Characterization of a Cellobiose Dehydrogenase and a New Xylanase. Enzyme and Microbial Technology, 31, 876-883.

https://doi.org/10.1016/S0141-0229(02)00208-9

[23] Wen, Z., Wu, M., Lin, Y., Yang, L., Lin, J. and Cen, P. (2014) Artificial Symbiosis for Acetone-Butanol-Ethanol (ABE) Fermentation from Alkali Extracted Deshelled Corn Cobs by Co-Culture of Clostridium beijerinckii and Clostridium cellulovorans. Microbial Cell Factories, 13, 92. https://doi.org/10.1186/s12934-014-0092-5

[24] Guragain, Y.N., Wilson, J., Staggenborg, S., McKinney, L., Wang, D. and Vadlani, P.V. (2013) Evaluation of Pelleting as a Pre-Processing Step for Effective Biomass Deconstruction and Fermentation. Biochemical Engineering Journal, 77, 198-207. https://doi.org/10.1016/j.bej.2013.05.014

[25] Brijwani, K. and Vadlani, P.V. (2011) Cellulolytic Enzymes Production via Solid-State Fermentation: Effect of Pretreatment Methods on Physicochemical Characteristics of Substrate. Enzyme Research, 2011, Article ID: 860134.

[26] Thota, M.P., Praneeth, S., Badiya, P.K., Yerram, S. and Vadlani, P.V. (2017) Macro-Micro Fungal Cultures Synergy for Innovative Cellulase Enzymes Production 
and Biomass Structural Analyses. Renewable Energy, 103, 766-773. https://doi.org/10.1016/j.renene.2016.11.010

[27] Vyas, A., Vyas, D. and Vyas, K.M. (2005) Production and Optimization of Cellulases on Pretreated Groundnut Shell by Aspergillus terreus AV49. Journal of Scientific \& Industrial Research, 64, 281-286. http://nopr.niscair.res.in/bitstream/123456789/5139/1/JSIR

[28] Oberoi, H.S., Babbar, N., Dhaliwal, S.S., Kaur, S., Vadlani, P.V., Bhargav, V.K. and Patil, R.T. (2010) Enhanced Oil Recovery by Pre-Treatment of Mustard Seeds Using Crude Enzyme Extract Obtained from Mixed-Culture Solid-State Fermentation of Kinnow (Citrus reticulata) Waste and Wheat Bran. Food and Bioprocess Technology, 5, 759-767.

[29] Rivilli, P.L., Alarcón, R., Isasmendi, G.L. and Pérez, J.D. (2011) Stepwise Isothermal Fast Pyrolysis (SIFP). Part II. SIFP of Peanut Shells-Antifungal Properties of Phenolic Fractions. BioResources, 7, 112-117.

[30] Guragain, Y.N., Srinivasa Rao, P., Vara Prasad, P. and Vadlani, P.V. (2017) Evaluation of Brown Midrib Sorghum Mutants as a Potential Biomass Feedstock for 2,3-Butanediol Biosynthesis. Applied Biochemistry and Biotechnology, 183, 1093-1110. https://doi.org/10.1007/s12010-017-2486-4

[31] Boonmee, A. (2012) Hydrolysis of Various Thai Agricultural Biomasses Using the Crude Enzyme from Aspergillus aculeatus iizuka FR60 Isolated from Soil. Brazilian Journal of Microbiology, 43, 456-466. https://doi.org/10.1590/S1517-83822012000200005

[32] Karimi, K. and Taherzadeh, M.J. (2016) A Critical Review on Analysis in Pretreatment of Lignocelluloses: Degree of Polymerization, Adsorption/Desorption, and Accessibility. Bioresource Technology, 203, 348-356. https://doi.org/10.1016/j.biortech.2015.12.035

[33] Karthika, K., Arun, A.B. and Rekha, P.D. (2012) Enzymatic Hydrolysis and Characterization of Lignocellulosic Biomass Exposed to Electron Beam Irradiation. Carbohydrate Polymers, 90, 1038-1045. https://doi.org/10.1016/j.carbpol.2012.06.040

[34] Ganguly, A., Das, S., Bhattacharya, A., Dey, A. and Chatterjee, P.K. (2013) Enzymatic Hydrolysis of Water Hyacinth Biomass for the Production of Ethanol: Optimization of Driving Parameters. Indian Journal of Experimental Biology, 51, 556-566. https://pdfs.semanticscholar.org/7101/b829b410c5cb068bd395fcf95a01d0f72ddb.pdf

[35] Guragain, Y.N., Ganesh, K.M., Bansal, S., Sai Sathish, R., Rao, N. and Vadlani, P.V. (2014) Low-Lignin Mutant Biomass Resources: Effect of Compositional Changes on Ethanol Yield. Industrial Crops and Products, 61, 1-8. https://doi.org/10.1016/j.indcrop.2014.06.014

[36] Mehrotra, R., Singh, P. and Kandpal, H. (2010) Near Infrared Spectroscopic Investigation of the Thermal Degradation of Wood. Thermochimica Acta, 507-508, 60-65. https://doi.org/10.1016/j.tca.2010.05.001

[37] Wu, Y., Yao, C., Hu, Y., Zhu, X., Qing, Y. and Wu, Q. (2014) Comparative Performance of Three Magnesium Compounds on Thermal Degradation Behavior of Red Gum Wood. Materials, 7, 637-652. https://doi.org/10.3390/ma7020637

[38] Thota, S.P., Thota, S.M., Srimadh Bhagavatham, S., Sai Manoj, K., Sai Muthukumar, V.S., Venketesh, S., Vadlani, P.V. and Belliraj, S.K. (2018) Facile One-Pot Hydrothermal Synthesis of Stable and Biocompatible Fluorescent Carbon Dots from Lemon Grass Herb. IET Nanobiotechnology, 12, 127-132. 